\title{
Conservation by trans-border cooperation: population genetic structure and diversity of geoffroy's bat (Myotis emarginatus) at its north-western european range edge
}

\author{
Alain C. Frantz ${ }^{1}$ (D) - Andrea Viglino ${ }^{2}$ (D) - Elodie Wilwert ${ }^{1}$ (D) Ana-Paula Cruz ${ }^{1}$. \\ Julian Wittische ${ }^{1,3}$ (D) Alexander M. Weigand ${ }^{1}$ (D) . Jacky Buijk' • Pierrette Nyssen ${ }^{4}$. \\ Daan Dekeukeleire ${ }^{5}$. Jasja J.A. Dekker ${ }^{6}$. Gavin J. Horsburgh ${ }^{7}$. \\ Simone Schneider ${ }^{1,8}$ (D) Mara Lang ${ }^{8} \cdot$ Romolo Caniglia9 $^{9}$ (D) Marco Galaverni ${ }^{10}$ (D) . \\ Anna Schleimer ${ }^{1}$ D . Szilárd-Lehel Bücs ${ }^{11}$ D . Jacques B. Pir ${ }^{1}$
}

Received: 5 August 2021 / Revised: 27 December 2021 / Accepted: 8 January 2022 /

Published online: 19 January 2022

(c) The Author(s) 2022

\begin{abstract}
In the European Union, all bat species are strictly protected and member states must ensure their conservation. However, if populations are genetically structured, conservation units that correspond to whole countries may be too large, putting small populations with specific conservation requirements at risk. Geoffroy's bat (Myotis emarginatus) has undergone well-documented declines at its north-western European range edge between the 1960 and 1990s and is considered to be negatively affected by habitat fragmentation. Here we analysed the species' genetic population structure and diversity to identify subpopulations with reduced genetic diversity and to scientifically inform conservation management. We generated 811 microsatellite-based genetic profiles obtained from 42 European nursery colonies and analysed a total of 932 sequences of the hypervariable region II of the mitochondrial control region sampled from across Europe. While two geographically widespread genetic populations were inferred to be present in north-western Europe, both nuclear and mitochondrial genetic diversity were lowest in the areas that had experienced a decline during the last century. A microsatellite-based analysis of demographic history did not permit, however, to unequivocally link that reduced genetic diversity to the population contraction event. Given the large geographic extent of the genetic populations, preserving the connectivity of mating sites requires concerted conservation efforts across multiple political jurisdictions. Genetic monitoring ought to be done on a regular basis to ensure that large-scale connectivity is maintained and further loss of genetic diversity is prevented.
\end{abstract}

Keywords Conservation genetics $\cdot$ Faecal DNA $\cdot$ Genetic diversity $\cdot$ Population structure $\cdot$ Notched-eared bat $\cdot$ Spatial ecology

Communicated by Dirk Sven Schmeller.

Extended author information available on the last page of the article 


\section{Introduction}

Bats (Chiroptera) perform important ecosystem-sustaining functions, including arthropod regulation, seed dispersal and pollination. Many species therefore provide unique and substantial ecological services to agricultural production (Kunz et al. 2011). However, due to their longevity, low rates of reproduction and high metabolic rates, bat populations are less resilient to threats arising from anthropogenic pressures, including land use change, urbanisation and persecution (Voigt and Kingston 2016). More than a third of all bat species are classified as threatened (or data deficient) and more than half have decreasing (or unknown) population trends (Frick et al. 2019). In the European Union, all bat species are strictly protected and member states must ensure their maintenance or the re-establishment of a favourable conservation status (Council of the European Communities 1992).

Small isolated populations are subject to loss of genetic diversity through inbreeding and genetic drift, limiting their adaptive potential and endangering their long-term survival (Frankham et al. 2009). In sedentary bats (i.e. bats that breed and hibernate within a $50-\mathrm{km}$ radius; Fleming 2019) the degree of gene flow, and hence population genetic structure, is determined by a species' dispersal capabilities as well as by mating strategies and historical processes (Moussy et al. 2013). There are thus examples of both lack (Castella et al. 2001; Rossiter et al. 2007; Ibouroi et al. 2018; Tournayre et al. 2019) and presence (Kerth and Petit 2005; Campbell et al. 2009; Meyer et al. 2009; Wright et al. 2018) of population genetic structure at smaller spatial scales. Understanding the degree of population structure across different parts of a species' range is, however, important to design adequate conservation strategies (Fahrig 2003). If conservation units are too large (e.g. because they correspond to whole countries) and contain geographically structured populations, small populations that require specific conservation efforts may be at risk (Rueness et al. 2003).

Geoffroy's or notched-eared bat (Myotis emarginatus) is a thermophilic species whose European distribution is centred on southern, south-western and central Europe (Fig. 1). Its northern range limit extends from the southern Netherlands, Belgium, Luxembourg, and southern Germany further to the east in southern Poland. During summer, the communally

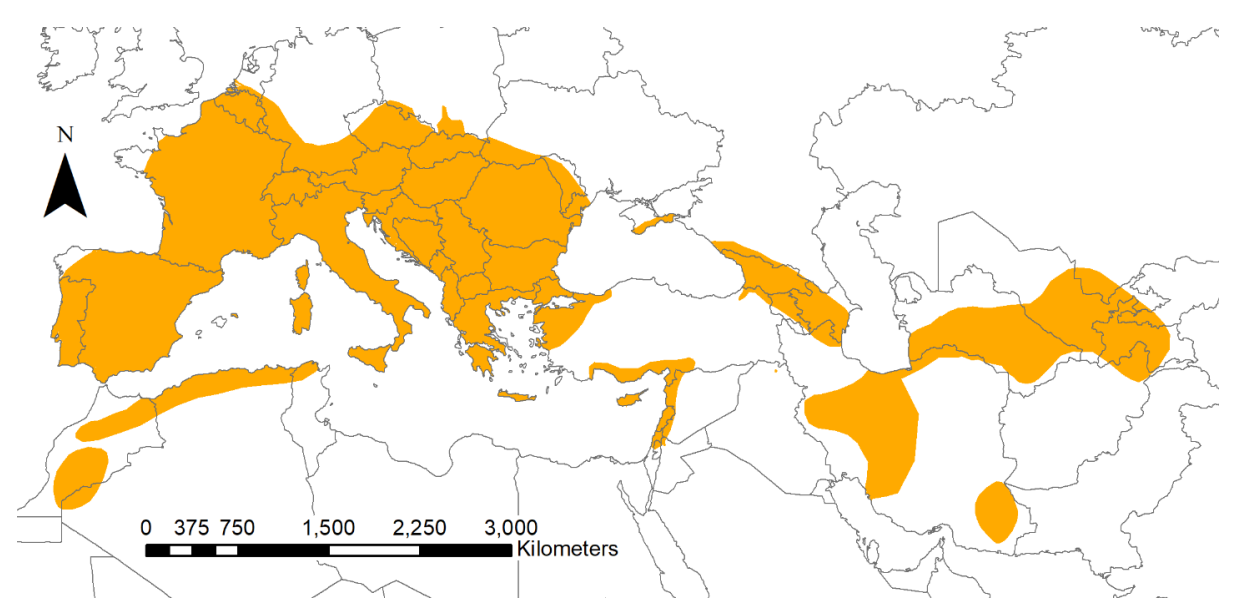

Fig. 1 Geographic distribution of Geoffroy's bat (Myotis emarginatus). Data taken from IUCN (2021) 
breeding females form nursery colonies while males remain solitary. Both sexes hibernate in caves and artificial subterranean habitats (Van Schaik 2015). Even though the species currently uses buildings as nursery colonies in northern Europe (Červený 1999, Dietz and Pir 2021), the analysis of faunal assemblages from cave sediments showed that it was present in northern Europe during the Holocene (Hutterer et al. 2012; Ochman 2003). The species can be considered sedentary, as nursery colonies and hibernation sites are typically within $40 \mathrm{~km}$ of each other (although distances of $>100 \mathrm{~km}$ have been reported; Červený 1999; Schunger et al. 2004).

While populations across much of the range of Geoffroy's bat seem to be stable (Piraccini 2016), countries on the species' north-western range edge — Belgium, Luxembourg and the Netherlands in particular - are confronted with specific threats and challenges. The bat's distribution along its northern range limit appears 'insular': it is abundant in certain regions, but rare or absent in adjoining areas (Pir and Dietz 2018). Similar to other range edge populations, populations of Geoffroy's bats in north-western Europe may thus exhibit low genetic diversity and high genetic differentiation as a result of geographic isolation and small effective population sizes (Eckert et al. 2008). Moreover, between the 1960 and 1990s, the species underwent well-documented strong population declines in Belgium and the Netherlands (Topál 2001), but numbers recovered again during the last decades (Van der Meij et al. 2015). Finally, Geoffroy's bat is considered to be negatively affected by habitat fragmentation (Meinig and Boye 2009) and Belgium, Luxembourg and the Netherlands are the European countries with the highest levels of landscape fragmentation (Jaeger and Madrinan 2011).

Our main objective was therefore to analyse the population genetic structure and the genetic diversity of Geoffroy's bat at the species north-western European range edge. We aimed to identify genetic factors that may have a negative impact on the conservation status of the species' in this region and to help define relevant conservation strategies. We hypothesised that, since the animals are located on the range edge, have small dispersal distances and are impacted by habitat fragmentation, the species is highly structured in north-western Europe, with subpopulations that have reduced genetic diversity. Furthermore, we tried to assess the influence of historical processes on current genetic patterns, hypothesising that recent decline caused by anthropogenic factors have left strong signals of demographic contraction in the genetic information.

\section{Methods}

\section{Sample collection}

Between 2016 and 2018, 1,945 faecal and 38 tissue samples were collected from Geoffroy's bats in 46 nursery colonies in seven northern and eastern European countries (colonies 1-46; Fig; 2) as well as from one nursery colony in Portugal (colony 47; Fig. 2) and Switzerland (colony 73; Fig. 2). Old faeces were covered with a plastic sheet the night before sample collection. In the morning, fresh faecal pellets were either put in $95 \%$ absolute ethanol or stored at $-80{ }^{\circ} \mathrm{C}$ one to three hours after collection. Sampling was performed from late May to early June before females gave birth to ensure that only adults were sampled. If possible, 50 samples per colony were collected (Online Resource Table S1). Additionally, 
38 mummified bats were collected in four colonies: Bech-Kleinmacher $(N=21$; colony 22 in Fig. 2), Marienthal ( $N=1$; colony 24), Rollingergrund ( $N=1$; colony 23 ) from Luxembourg and Veaugues ( $N=15$; colony 37$)$ in France. Because one German colony ("Waldfeucht") was located near the Dutch border (Fig. 2), we will, for ease of reference, refer to this colony as being Dutch.

\section{Laboratory work}

In order to avoid contamination of the faecal DNA samples and reagents, we used a laboratory free of concentrated bat DNA or PCR product to perform the extractions and prepare the polymerase chain reactions (PCRs). Negative controls were included at every stage of the analysis to monitor contamination. DNA was extracted from tissue samples using an ammonium acetate-based salting-out procedure (Miller et al. 1988). DNA was extracted from faecal samples following an approach by Luikart et al. (2008). Faecal pellets were initially washed for $15 \mathrm{~min}$ in $200 \mu 1$ lysis buffer $(0.1 \mathrm{M}$ Tris-HCl, 0.1 M EDTA, $0.01 \mathrm{M} \mathrm{NaCl}$, $1 \% \mathrm{~N}$-lauroyl sarcosine, $\mathrm{pH} 7.5)$. Approximately $180 \mu \mathrm{l}$ of the lysis buffer were then added to the DNeasy blood and tissue kit (Qiagen, Hilden, Germany) and the DNA extraction was performed following the manufacturer's protocol. DNA was eluted in $200 \mu$ l storage buffer.

All samples were genotyped using 13 microsatellite markers (Online Resource Table S2). As the study was based mostly on non-invasive sampling, twelve markers with a short amplification product were specifically developed for this work, following procedures outlined in Online Resource Appendix S1. We also included locus H29, which had originally been developed for M. myotis by Castella and Ruedi (2000). The methods employed to genotype the 13 loci are given in Online Resource Appendix S2. The DNA obtained from faecal samples is generally low in quality and quantity, leading to genotyping errors during the PCR (Frantz et al. 2003), such as the non-amplification of an allele (allelic dropout) or the generation of artefacts resembling real alleles (false alleles; Broquet and Petit 2004). In order to avoid these problems and to ensure reliable genetic profiles, the loci were amplified repeatedly (Frantz et al. 2003). Given the large number of samples collected, we only attempted to obtain a consensus profile for the samples with the best DNA quality. For those colonies where sufficient samples were available, we aimed to obtain a consensus genetic profile for between 20 and 24 individuals. For other colonies, we aimed to generate the maximum possible number of genetic profiles. The procedure adopted to ensure the reliability of the genetic profiles is summarised in Online Resource Appendix S3.

We designed the primers CR.HVII.F (5'-ACGGCATCTGGTTCTCACTTC-3') and CR.HVII.R (5'- GCGTATGCGTATGCTCCTTG-3') to amplify a 383-base-pair-long fragment of the second hypervariable segment (HVII) of the mitochondrial (mt) control region. Between two and 23 individuals (median: 15) from 44 nursery colonies were sequenced (Online Resource Table S1). Following microsatellite genotyping, all sequences were known to have originated from different individuals. We managed to obtain sequences from five colonies whose faecal DNA was not of sufficient quality and quantity to generate reliable and complete multi-locus genetic profiles (Fig. 2; Online Resource Table S1). In those cases, we only sequenced the HVII fragment in samples where the genotyping had worked sufficiently well to infer that the samples originated from different individuals (e.g. consensus genotype obtained for three or four loci). While microsatellite genotyping of the fifteen tissue samples collected in central France (Veaugues) was unsuccessful-perhaps because 


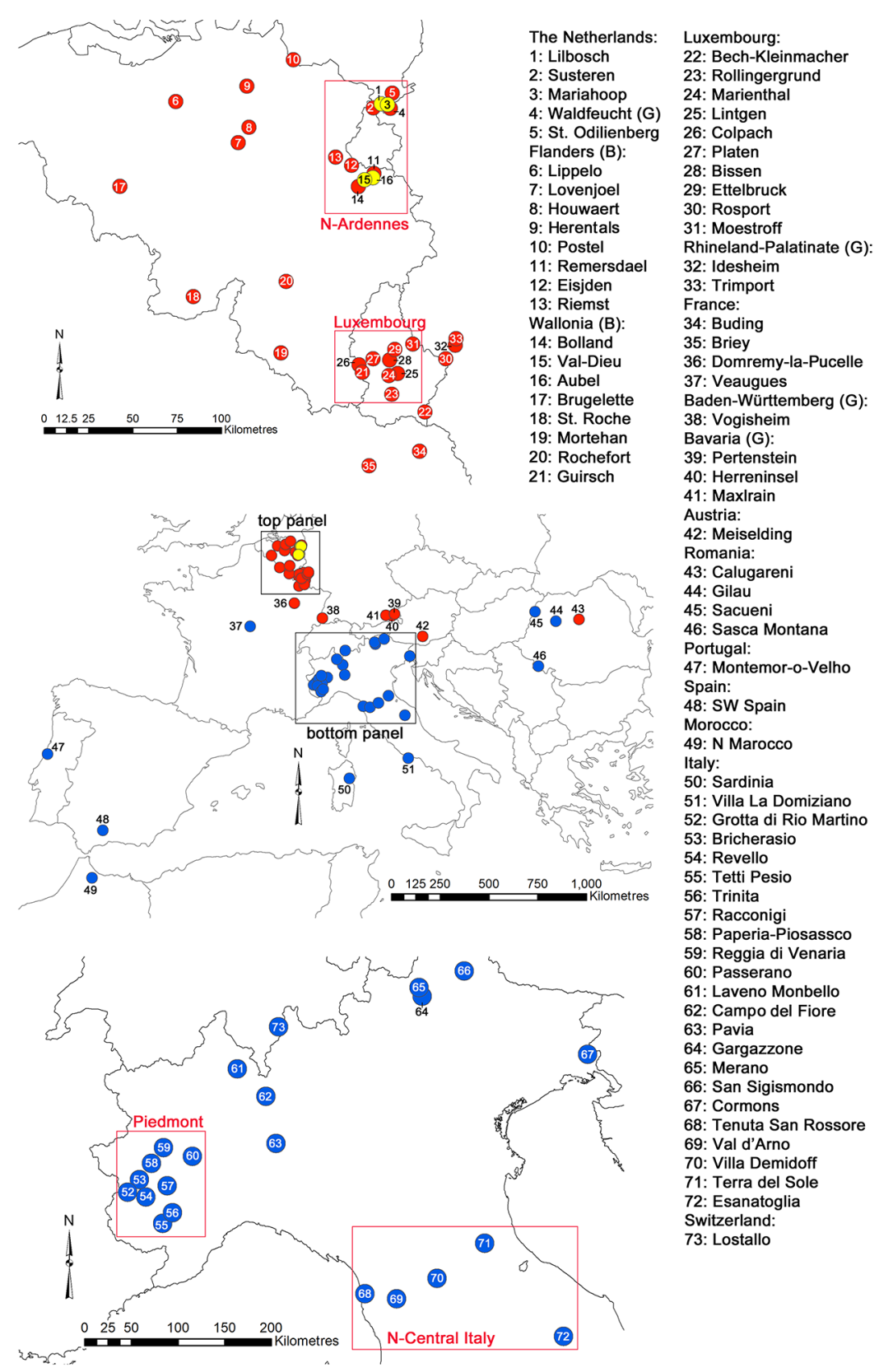

Fig. 2 Geographic distribution of the 73 Myotis emarginatus colonies included in this study. The two rectangles in the middle panel show the geographic location of the upper and lower panel, respectively. Red colonies: microsatellite-based genetic profiles and sequences of the second hypervariable segment (HVII) of the mitochondrial control region were available for analysis. Yellow colonies: only microsatellite profiles available for analysis. Blue colonies: only HVII sequences available for analysis. The red squares show the geographic location of the pre-defined populations for the phylogeographic analysis based on the HVII. The letter in brackets indicates the country where a colony or region is located $(\mathrm{G}=\mathrm{Germany}, \mathrm{B}=\mathrm{Belgium})$ 
the samples had been stored in methylated ethanol - it was possible to sequence the HVII fragment in these samples. The laboratory methods for sequencing the HVII fragment are outlined in Online Resource Appendix S2.

\section{Data analysis: microsatellite loci}

We used the 21 colonies with $>20$ reliable genetic profiles to test each locus for heterozygote deficiency or excess using the Markov chain method in genepop v3.4 (Raymond and Rousset 1995), with 10,000 dememorisation steps, 500 batches and 10,000 subsequent iterations. The same 21 colonies were tested for linkage disequilibria among loci using an exact test based on a Markov chain method implemented in genepop. The false discovery rate technique was used to limit false assignment of significance by chance (Verhoeven et al. 2005).

We estimated the most-likely number of genetic clusters $(K)$ using structure v. 2.3.4 (Pritchard et al. 2000), conducting ten independent runs of $K=1-10$ with $10^{6}$ Markov chain Monte Carlo (MCMC) iterations after a $10^{5}$-iteration burn-in, using the admixture and correlated-allele-frequency models. ALPHA, the Dirichlet parameter for the degree of admixture, was allowed to vary between clusters. The most probable number of clusters was chosen based on the ten log-likelihood values inferred for each $K$ and their convergence across runs. After accounting for label switching and confirming the lack of multimodality, the assignment probability of each individual to the detected clusters was estimated as the individual's proportion of membership averaged over the ten runs. We also used baps v6.0 (Corander et al. 2004) to partition the data at the colony level, which clusters the sampling units into populations with non-identical allele frequencies (Corander et al. 2004). The program was run 10 times for each $K=2-20$, using the colonies as predefined groups. We used genetix v.4.05.2 (Belkhir 2004) to perform a factorial correspondence analysis (FCA) to visualise the genetic distance between the summer colonies for which reliable consensus genotypes were generated.

To test for isolation-by-distance (IBD), we used spagedi v.1.5 (Hardy and Vekemans $2002)$ to calculate the regression of $F_{\mathrm{ST}} /\left(1-F_{\mathrm{ST}}\right)$ estimates $-F_{\mathrm{ST}}$ estimated following Weir and Cockerham (1984)- for pairs of nursery colonies against the logarithm of the geographic distance between them (Rousset 1997) and tested the slope for a significant difference from zero through 10,000 permutations of individual locations. We calculated unbiased expected heterozygosities $\left(\mathrm{u} H_{\mathrm{E}}\right.$; Nei 1978) using genetix and used fstat v.2.9.3.2 (Goudet 1995) to calculate allelic richness $(A \mathrm{r})$. These summary statistics were calculated for the 38 colonies for which $\geq 10$ genetic profiles were available, and the estimates of allelic richness were therefore based on 10 individuals in each colony.

To infer past demographic change, we used the microsatellite data to conduct a maximum-likelihood inference using the software migraine v.0.6 alongside the blackbox R package (Rousset and Leblois 2012; Leblois et al. 2014). This method is based on importance sampling of gene genealogies for which we chose a stepwise mutation model. We excluded two loci with a four-base-pair repeat motif (Mema5 and Mema32) from this analysis, as their repeat length variations were not consistent multiples of four. An IBD pattern increases the rate of false contraction detection, unless the whole population area is sampled (Leblois et al. 2014). We performed the analysis on three of the inferred genetic populations ('Bavaria', 'B/NL' and 'L/RLP/F'; see Results). For the L/RLP/F cluster, we excluded a 
geographic outlier (the 'Vogisheim' colony) from the analysis to eliminate the IBD pattern between colonies in the L/RLP/F cluster (see Results). We also excluded the 'Mortehan' colony from this analysis, due to its potentially confounding admixed ancestry (see Results). While the B/NL cluster was characterised by an IBD pattern, we have sampled the whole population area of the species in Belgium and the Netherlands, thus allowing meaningful analysis of demographic change in this cluster (Leblois et al. 2014).

We used the maximum-likelihood inference method to estimate four different parameters related to population size contraction: the current population size $N$ scaled by the mutation rate $\mu$ of the markers $(2 N \mu)$, the time in generations since the end of the demographic change $\left(T_{\mathrm{g}}\right)$ scaled by the current population size $\left(T_{\mathrm{g}} / 2 N\right)$, the duration of the demographic event in generations $\left(D_{\mathrm{g}}\right)$ scaled by the current population size $\left(D_{\mathrm{g}} / 2 N\right)$, and the ancestral population size scaled by the mutation rate of the markers $\left(2 N_{\text {and }} \mu\right)$. We also inferred the secondary parameters $T_{\mathrm{g}} \mu$ and $D_{\mathrm{g}} \mu$. It should be noted that, as $N$ corresponds to the number of gene copies, $2 N$ represents four times the number of individuals. To evaluate the performance of the maximum-likelihood inference we also measured the observed root mean square error of prediction of log-likelihood and a "goodness of prediction" which computes the root mean ratio of the theoretical square error of the kriging procedure over the observed error of the fit. Because the number of parameter points at which likelihood is computed influences results, we chose 2,500 as a meaningful compromise between having enough points in the parameter range to build accurate confidence intervals, while keeping the goodness of prediction below 100 (Table 1), which tends to increase with the number of points (see latest migraine documentation). We ran three full iterations for each analysis, allowing each new iteration to reuse the results from previous runs in order to refine the analysis.

\section{Data analysis: mitochondrial DNA}

In addition to the sequences generated de novo during this study, we obtained a further 342 HVII sequences from a study by Viglino (2012) which originated from 23 sites in Italy (colonies 50-72: Fig. 2) as well as from Spain and Morocco (colonies 48 and 49, Fig. 2). Sampling was both invasive (mist-net trapping, wing punches) and non-invasive (faecal samples; Online Resource Table S3). The authors microsatellite-genotyped their faecal DNA samples (Viglino et al. 2016), thus ensuring that their HVII sequences were from unique individuals. Between four and 33 sequences were available per locality.

A median-joining haplotype network was generated using popart (Leigh and Bryant 2015). Ten geographic groups were plotted on the haplotype network as traits (group I: localities 1-18, 20; II: 19, 21-36, 38; III: 37; IV: 39-41; V: 42-46; VI: 47+48; VII: 49; VIII: 50; IX: 51, 68-72; X: 52-67, 73), being either defined by shared population affiliation (based on microsatellite data) or by geographic proximity. The annotation of haplotypes was kept consistent with Viglino (2012), with new haplotypes consecutively added.

We pre-defined four geographical groups ('North of Ardennes', localities 1-5, 11-16; 'Luxembourg', 21, 23-29, 31; 'Piedmont' in Western Italy, 52-60; 'Northern Central Italy', 68-72; Fig. 2) to investigate differences in haplotype and nucleotide diversity on a latitudinal gradient, in order to account for differences in sampling intensity (i.e. number of populations and specimens analysed in a given area). dnasp v.6.12.03 (Rozas et al. 2017) was used to calculate the number of segregating sites $(S)$, the number of haplotypes $(H)$, haplotype 


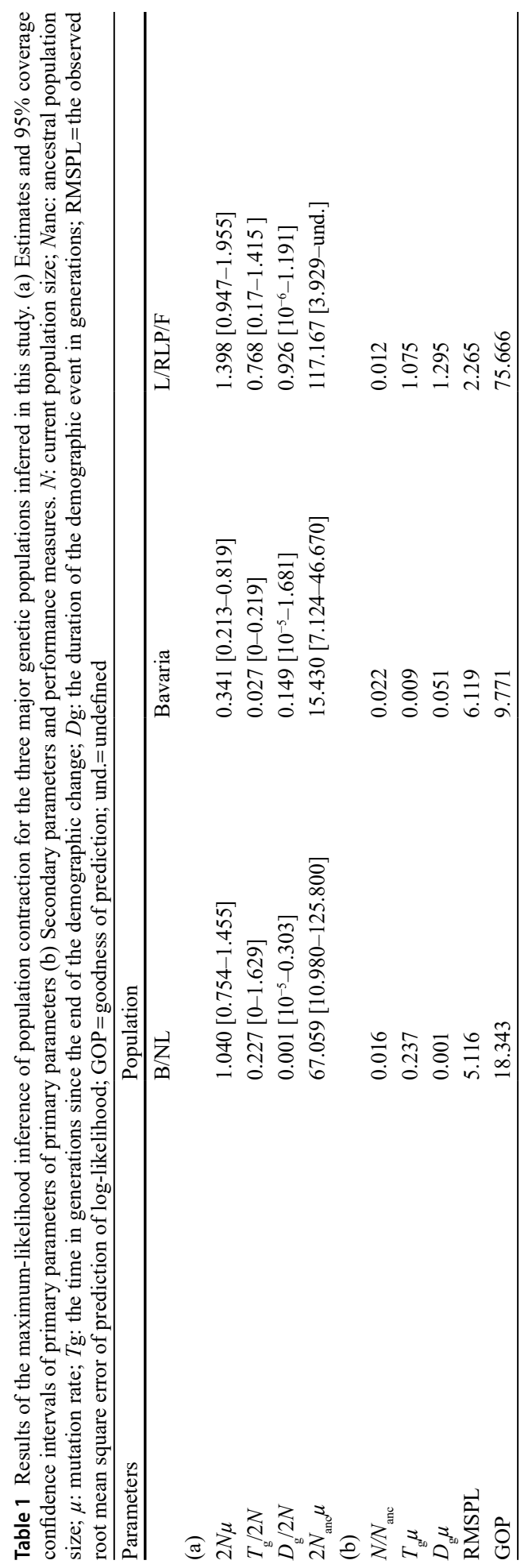


diversity $\left(H_{\mathrm{d}}\right)$ and nucleotide diversity $(\pi)$. $\Phi_{\mathrm{ST}}$ estimates between nursery colonies were obtained using arlequin v.3.5.2.2 (Excoffier et al. 2005).

We used dnasp to calculate test statistics for neutral molecular evolution: Fu's $F_{\mathrm{S}}(\mathrm{Fu}$ 1997), Tajima's $D$ (Tajima 1989), Fu \& Li's $D^{*}$ and $F^{*}$ (Fu and $\mathrm{Li} 1993$ ). $D^{*}$ and $F^{*}$ were based on biallelic positions only. dnasp was also used to test the observed mismatch distribution against a null model for historically expanding populations (Rogers and Harpending 1992) using the goodness-of-fit parameters of Harpending's raggedness index hri (Harpending 1994) and the $R^{2}$ statistic (Ramos-Onsins and Rozas 2002). Significance values of the test statistics were calculated using 1,000 coalescent simulations.

\section{Results}

\section{Microsatellite genotyping}

After two initial amplification reactions, 903 of the 1945 DNA samples (46\%) were retained for the generation of consensus genetic profiles. In 626 of these, all genotypes generated at individual loci were identical. In order to obtain consensus genetic profiles from 903 faecal DNA samples, we generated 26,498 genotypes, of which 25,757 (97.2\%) did not contain an apparent genotyping error. Altogether 138 genotypes contained an obvious spurious allele while 193 genotypes had a case of allelic drop-out. It was not possible to generate a reliable consensus genotype for 260 loci in 130 genetic profiles.

The 903 consensus genotypes originated from 788 unique individuals in 42 colonies. The faecal DNA samples from five colonies (colonies 44-46 from Romania, colony 47 from Portugal, colony 73 from Switzerland; Fig. 2) were not of sufficiently high quality or quantity to allow the generation of consensus genotypes. We generated between seven and 31 reliable consensus genotypes per remaining colony. After the inclusion of 23 genetic profiles obtained from tissue DNA, we generated a dataset consisting of 811 genetic profiles.

\section{Population genetic structure and diversity}

After correcting for multiple tests, 11 loci did not deviate significantly from expected Hardy-Weinberg (HW) proportions in any of the 21 tested colonies (Online Resource Table S4). The loci Mema22 and Mema39 significantly deviated from HW proportions in one and three of the 21 colonies, respectively. After correcting for multiple tests, one pair of (different) loci was in linkage disequilibrium in two colonies only. Given the lack of systematic problems, all loci were retained for further analysis.

structure did not provide clear support for a specific number of clusters (Fig. 3a). At $K=3$, the log-likelihood values reached a plateau and converged well in all but one run (which was omitted from further analysis). However, log-likelihood values continued to increase slightly at $K=4$ and $K=5$, respectively. While admixture levels were relatively high at $K=3$ (and at $K=4$ and $K=5$ ), the algorithm inferred three geographically coherent genetic populations (Fig. 3b). All the colonies (bar two) from the Netherlands (NL) and Belgium (B) formed one cluster, while the individuals from two colonies in southern Belgium (Mortehan, Guirsch), Luxembourg (L), Rhineland-Palatinate (RLP), Baden-Württemberg (both Germany) and France (F) formed another. For ease of reference, we will refer to the 
(a)

(b)

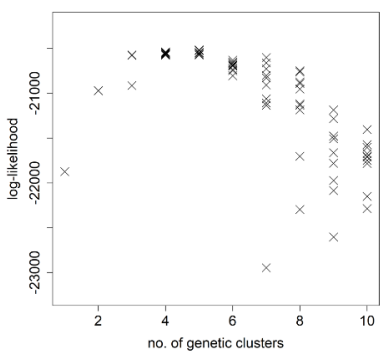

STRUCTURE $K=3$
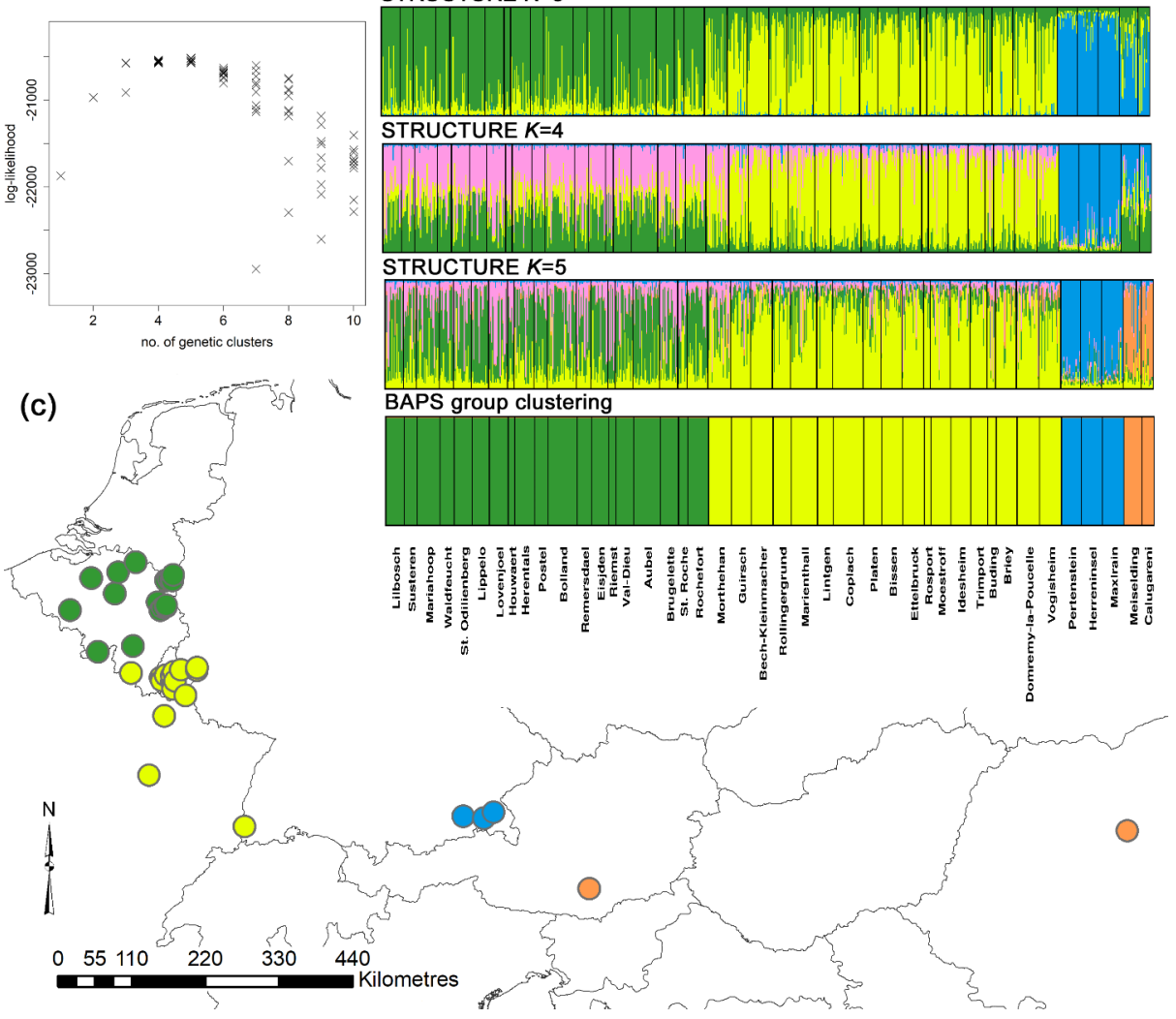

STRUCTURE $K=\mathbf{5}$

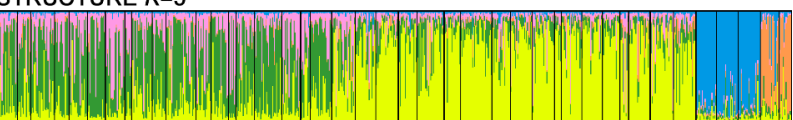

BAPS group clustering
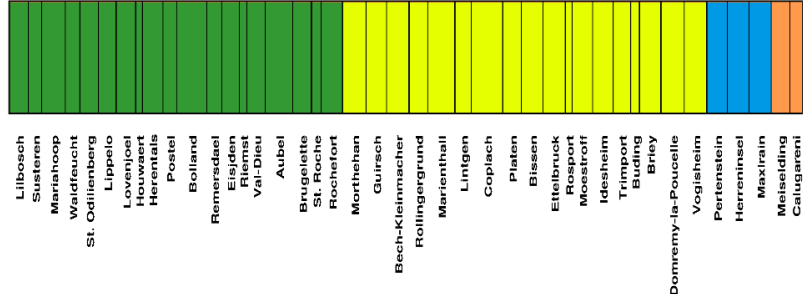

Fig. 3 Results of the analysis of the population genetic structure of M. emarginatus in its northern European distribution. (a) Plot of the number of STRUCTURE clusters tested against their estimated log-likelihood. (b) Summary of the assignment analysis of STRUCTURE (for $K=3-5$ ) and the group-based clustering in BAPS. Each individual is represented by a single vertical line, representing the individual's estimated proportion of membership to the genetic cluster and the different colours represent different genetic clusters. (c) Geographic distribution of the clusters derived using the group-based clustering in BAPS. Colours correspond to the clusters in the assignment plots

former cluster as 'B/NL' and to the latter as ' $\mathrm{L} / \mathrm{RLP} / \mathrm{F}$ '. Finally, the colonies from southeastern Germany (Bavaria), Austria and Romania formed a third partition. At $K=4$ and $K=5$, structure generally split these three clusters in a biologically non-meaningful way. However, at $K=5$, structure also split the German (Bavaria), Austrian and Romanian colonies into two additional coherent clusters, the first one consisting of the Bavarian and the second one of the Austrian and Romanian colonies.

The group-based clustering in the program baps inferred the presence of four clusters with a probability of $P(1.0)$. This second algorithm partitioned the data in a similar way to structure, inferring the presence of the B/NL and L/RLP/F clusters, as well as a 'Bavarian' and an 'Austrian/Romanian' cluster (Fig. 3b and c). The colony-based FCA analysis confirmed the genetic differentiation of the four clusters inferred by baps (Fig. 4). Moreover, it inferred that the 'Lippelo' and 'Riemst' nursery colonies were outliers of the B/NL cluster 


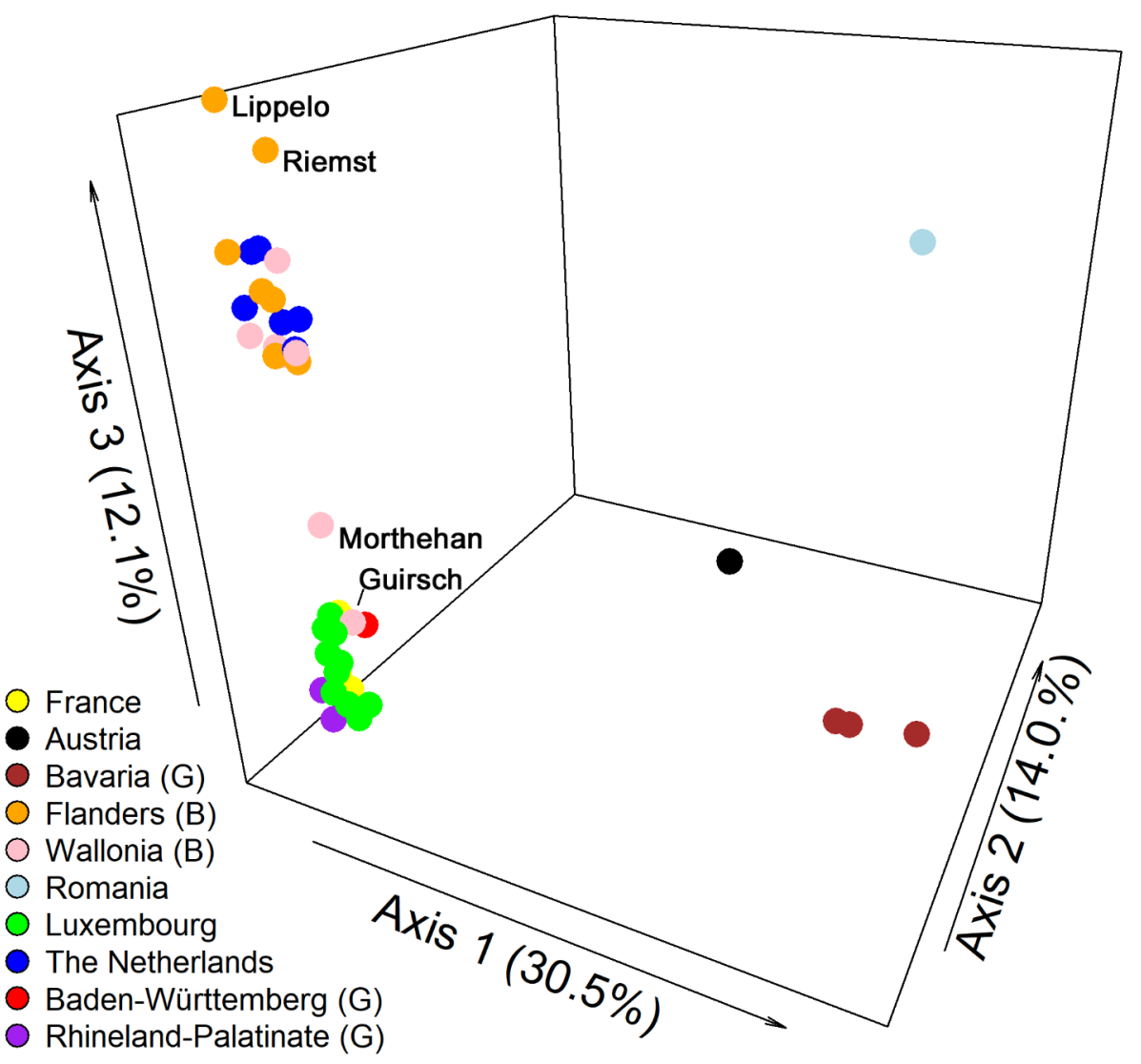

Fig. 4 Factorial correspondence analysis of microsatellite-based genetic profiles generated for 42 European summer colonies of Myotis emarginatus. The percentage of the total variation explained by each of the three axes is indicated. The letter in brackets indicates the country where a region is located $(\mathrm{G}=\mathrm{Germany}$, $\mathrm{B}=$ Belgium)

and that the 'Mortehan' colony was an outlier of the L/RLP/F cluster, which the structure assignment plot suggested had a number of individuals with admixed ancestry. We used the baps partition as a basis for further analysis.

Overall, the microsatellite dataset was characterised by a significant IBD pattern (slope \pm s.e. $=0.035 \pm 0.005, P<0.001)$. The strength of the relationship was mainly driven by pairs of colonies belonging to different genetic clusters (Fig. 5a). However, there was also a significant IBD pattern between colonies in the B/NL cluster (slope \pm s.e. $=0.0080 \pm 0.003$, $P=0.015$ ), even when excluding 'Lippelo' and 'Riemst', the colonies identified as genetic outliers in the FCA (slope \pm s.e. $=0.006 \pm 0.003, P=0.019$; Fig. $5 b$ ). The L/RLP/F cluster was also characterised by a significant IBD pattern (slope \pm s.e. $=0.009 \pm 0.003, P=0.008$; Fig. 5c), which was, however, driven by a geographic outlier. Indeed, when excluding the 'Vogisheim' colony in south-western Germany, the IBD pattern between the remaining colonies in the $\mathrm{L} / \mathrm{RLP} / \mathrm{F}$ cluster was not significant (slope \pm s.e. $=0.003 \pm 0.002, P=0.137$; Fig. 5c). 
(a)

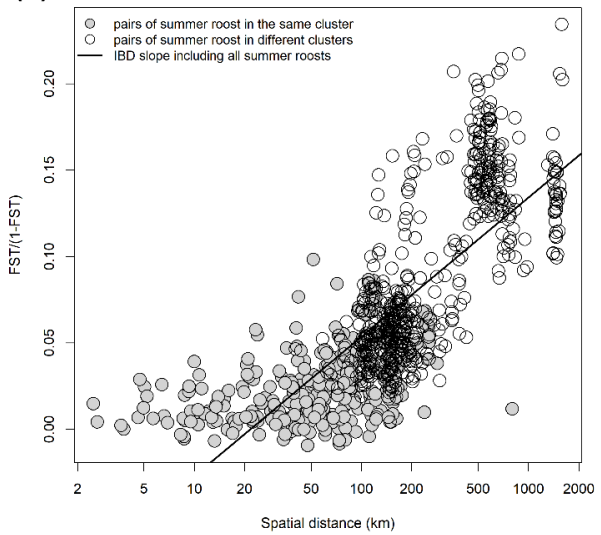

(c)

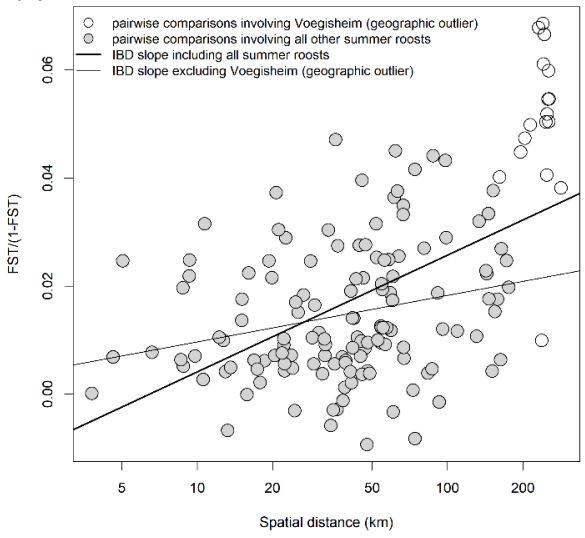

(b)

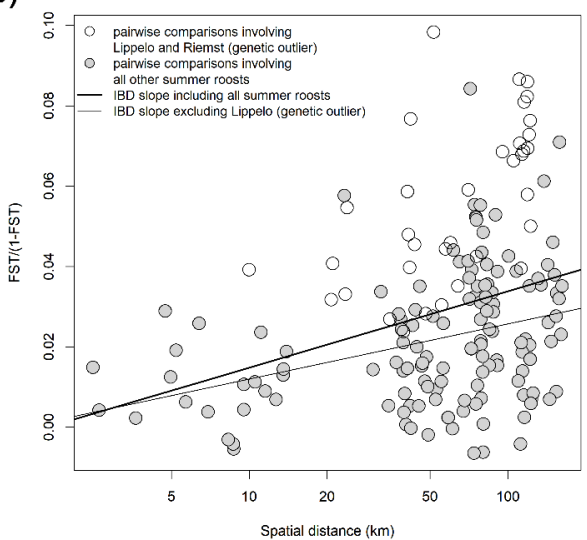

Fig. 5 Relationship between genetic and geographic distance for pairs of European Myotis emarginatus summer roosts. (a) Pairwise comparisons of all 42 colonies for which microsatellite-based genetic profiles were available. (b) Pairwise comparisons of the 19 colonies that had been assigned to the Belgian/Netherlands (B/ NL) cluster by BAPS (c) Pairwise comparisons of the 18 colonies that had been assigned to the Luxembourg/ Rhineland-Palatinate/France (L/RLP/F) cluster by BAPS

There was an apparent gradual decline in nuclear genetic diversity from the east to the northwest of the study area, with the B/NL cluster being the least genetically diverse (Fig. 6). This decline was observed for allelic richness, with the eastern-most colony in Romania having the highest allelic richness $\left(A_{\mathrm{r}}=4.4\right)$ and the north-western-most colony 'Lippelo' the lowest $\left(A_{\mathrm{r}}=2.6\right)$. While the Bavarian colony of 'Maxlrein' had the highest unbiased expected heterozygosity $\left(\mathrm{u} H_{\mathrm{e}}=0.60\right)$, there was also a decline in $\mathrm{u} H_{\mathrm{e}}$ from the east of the study area (Austria, Bavaria and Romania) to the northwest, with 'Lippelo' again having the lowest diversity value $\left(\mathrm{u} H_{\mathrm{e}}=0.418\right)$. Unbiased expected heterozygosity values ranged from 0.54 to 0.52 in the $\mathrm{L} / \mathrm{RLP} / \mathrm{F}$ cluster and from 0.53 to 0.42 in the $\mathrm{B} / \mathrm{NL}$ cluster.

Bavaria was characterised by the lowest, and L/RLP/F by the highest population sizes both in the past and the present (Table 1). The estimates of current and past scaled population sizes were relatively precise, with the exception of the past scaled population sizes for $\mathrm{L} / \mathrm{RLP} / \mathrm{F}$ which presented an undefined upper confidence interval bound, indicating a 

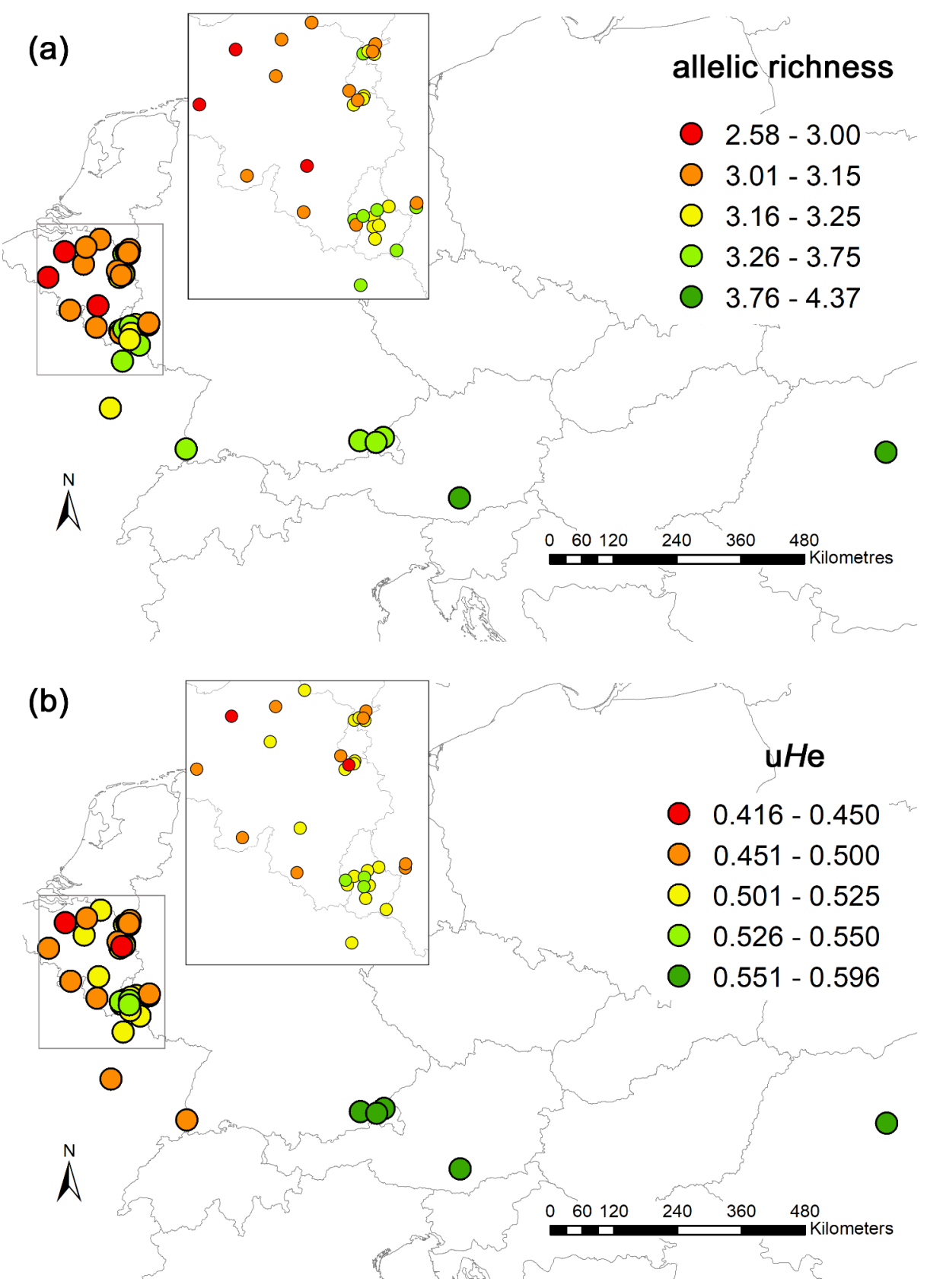

Fig. 6 Distribution of (a) allelic richness and (b) unbiased expected heterozygosity values in the 38 Myotis emarginatus summer colonies for which ten or more microsatellite genetic profiles were available. The estimates of allelic richness were therefore based on 10 individuals in all the colonies. The inset in each map magnifies the area in the smaller grey-contoured box

potentially very large past population size (Table 1; Online Resource Figs. S1-S3). Based 
on the point estimates, the ratios of the current and past scaled population sizes indicate that the current population size is below $5 \%$ of the ancestral population size in all three populations. The time since the start of the decline scaled by the mutation rate (secondary parameter $T_{\mathrm{g}} \mu$ ) was highest for $\mathrm{L} / \mathrm{RLP} / \mathrm{F}$ and lowest for Bavaria. The Bavarian point estimate was two orders of magnitude smaller than the B/NL estimate, suggesting that the Bavarian decline may have happened rather recently. However, the confidence intervals of the primary parameter $T_{\mathrm{g}} / 2 \mathrm{~N}$ for both Bavaria and B/NL included zero in their lower bound and we can thus not exclude the possibility that the start of the population contraction may have been very recent in both cases, and that the decline is ongoing (Table 1; Online Resource Figs. S1-S3). In contrast, the decline in the L/RLP/F population very likely occurred much earlier than in the other two populations and may have occurred in pre-industrial or perhaps even pre-historical times, depending on the chosen mutation rate values. The estimates of the duration of the demographic change were too imprecise to allow trustworthy conclusions (Table 1; Online Resource Figs. S1-S3).

\section{Mitochondrial diversity}

A 308-bp-long sequence of the hypervariable region II of the mitochondrial control region was generated de novo for 590 samples, leading to a final dataset comprising 932 mitochon-

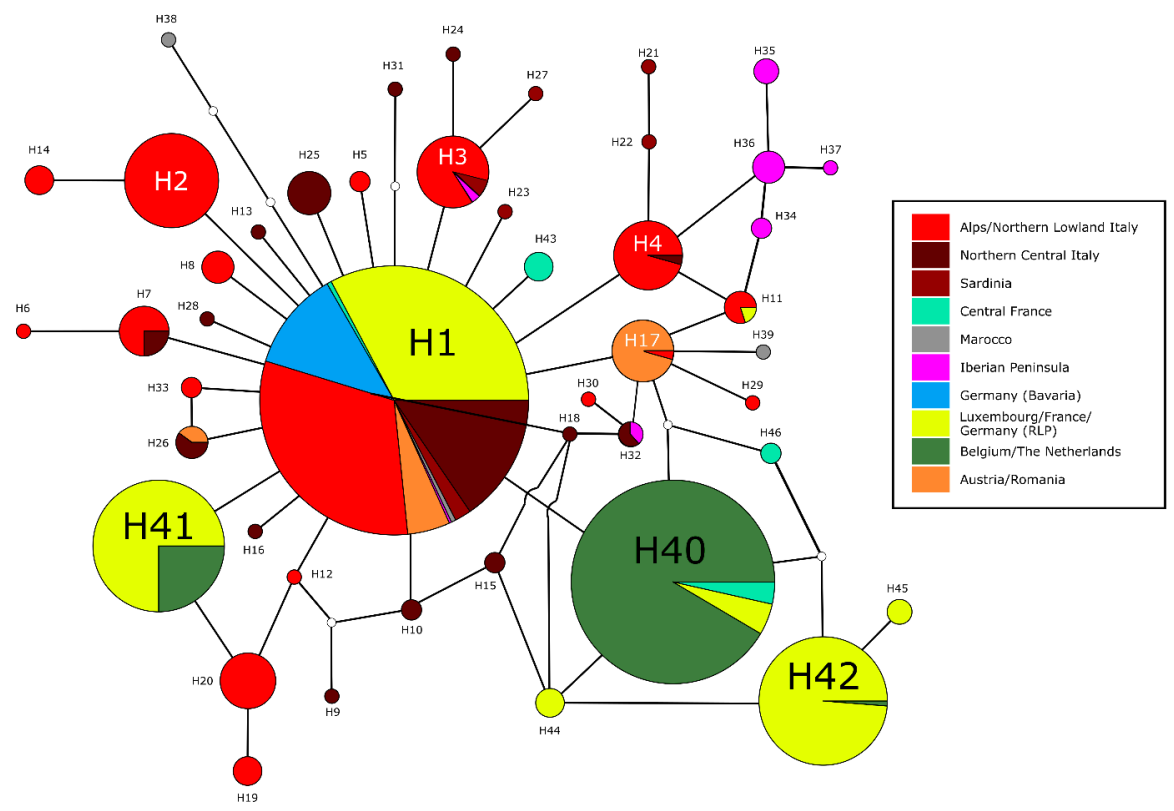

Fig. 7 Median-joining haplotypwe network of the mitochondrial hypervariable region II of Myotis emarginatus sampled in 69 European summer colonies. The ten colour-coded geographic groups were defined based either on shared genetic cluster affiliation (based on microsatellite data; see Fig. 2) or based on geographic proximity. The size of the circles is proportional to the frequency of the respective haplotype (H1H46) in the total dataset. The mutational pathway interconnecting haplotypes is represented by a thin black line; hypothetical but unsampled haplotypes are given as white dots 
drial HVII control region sequences from 69 nursery colonies (Online Resource Table S1). The sequences formed 46 haplotypes, of which 39 had already been reported by Viglino (2012), while seven new haplotypes were detected in this study (H40-H46). All haplotypes are available on GenBank (accession numbers.: OL889586-OL889631). We found evidence for only a single European haplotype group. The haplotype network (Fig. 7) was characterised by a star-like pattern, with two highly frequent (H1, H40) and several rarer haplotypes. The single most frequent haplotype $\mathrm{H} 1$ was shared by individuals from the Iberian Peninsula, Morocco, the Italian mainland, Sardinia, the north-western range edge and eastern Europe. Four of the seven haplotypes observed at the north-eastern range edge of Geoffroy's bat were specific to this region (H41, H42, H44 and H45).

Overall, nucleotide diversity was low, but haplotype diversity moderately high (Table 2). When focussing on the four pre-defined groups, a generally high $H_{\mathrm{d}}$ was found in Northern Central-Italy and in Piedmont, which hosted several endemic haplotypes, as well as in Luxembourg (Table 2). The number of haplotypes declined from south to north, although the number of investigated specimens increased along this latitudinal gradient. When compared to the pre-defined Italian groups North-Central Italy and Piedmont, nucleotide diversity in Luxembourg was 2.17 and 2.71 times higher, respectively. A remarkably low haplotype and nucleotide diversity was observed in the group 'North of Ardennes', with only two haplotypes detected in 102 investigated specimens. In the L/RLP/F cluster $\Phi_{\mathrm{ST}}$ estimates between colonies ranged between 0 and 0.859 , with a median of $\Phi_{\mathrm{ST}}=0.319$.

All four tests for neutral molecular evolution $\left(F_{\mathrm{s}}, D, D^{*}\right.$ and $\left.F^{*}\right)$ were significantly negative, which can be interpreted as evidence for past population expansion (Table 3). The mismatch distribution revealed a unimodal pattern with a high frequency of almost similar mitochondrial haplotypes, as is to be expected under a model of population expansion.

Table 2 Genetic diversity estimates of Myotis emarginatus based on the hypervariable region II of the mitochondrial control region. Results are presented for the complete mitochondrial dataset and for four predefined study populations. The geographic location of the pre-defined populations can be found in Fig. 1

\begin{tabular}{lcrlrrll}
\hline Population & $N_{\text {colonies }}$ & $N_{\text {indiv }}$ & $\mathrm{GC}(\%)$ & \multicolumn{1}{l}{$\mathrm{S}$} & \multicolumn{1}{l}{$\mathrm{H}$} & \multicolumn{1}{l}{$H_{\mathrm{d}}$} & $\pi$ \\
\hline Complete dataset & 69 & 932 & 44.7 & 36 & 46 & $0.794 \pm 0.010$ & $0.0054 \pm$ n.d. \\
North of Ardennes & 11 & 102 & 45.1 & 2 & 2 & $0.179 \pm 0.047$ & $0.0012 \pm 0.0003$ \\
Luxembourg & 9 & 148 & 44.9 & 6 & 5 & $0.689 \pm 0.000$ & $0.0076 \pm 0.0002$ \\
Piedmont & 9 & 119 & 44.8 & 7 & 8 & $0.618 \pm 0.040$ & $0.0035 \pm 0.0004$ \\
Northern-Central Italy & 5 & 70 & 44.5 & 18 & 14 & $0.608 \pm 0.065$ & $0.0028 \pm 0.0005$ \\
\hline
\end{tabular}

$N_{\text {colonies }}:$ number of colonies included in the analysis. $N_{\text {indiv }}:$ number of sequences analysed, GC(\%): GCcontent, $\mathrm{S}$ : number of segregating sites, $\mathrm{H}=$ number of haplotypes, $H_{\mathrm{d}}$ : haplotype diversity, $\pi=$ nucleotide diversity. Standard deviations are indicated for $H_{\mathrm{d}}$ and $\pi$

Table 3 Test statistics for neutral molecular evolution and goodness-of-fit parameters for the complete European Myotis emarginatus haplotype dataset of the hypervariable region II of the mitochondrial control region. Significant values are in bold

\begin{tabular}{lllllllll}
\hline & \multicolumn{1}{l}{ Statistic } & & & & & \\
\hline & $F_{\mathrm{S}}$ & $D$ & $D^{*}$ & $F^{*}$ & $h r i$ & $R^{2}$ \\
Estimate & $\mathbf{- 3 4 . 0 1 8}$ & $\mathbf{- 1 . 7 5 0}$ & $\mathbf{- 5 . 1 9 4}$ & $\mathbf{- 4 . 3 8 7}$ & 0.063 & 0.023 \\
$P$-value & $<0.001$ & 0.001 & $<0.001$ & $<0.001$ & 0.196 & 0.072 \\
\hline
\end{tabular}

$F_{\mathrm{s}}=$ Fu's $F_{\mathrm{s}} ; D=$ Tajima's $D ; D^{*}=\mathrm{Fu} \&$ Li's $D^{*} ; F^{*}=$ Fu \& Li's $F^{*} ;$ hri=Harpending's raggedness index; $R^{2}=R^{2}$ statistic 
Both goodness-of-fit parameters $h r i(0.0632, p=0.196)$ and $R^{2}(0.0226, p=0.072)$ did not significantly deviate from zero, indicating that the observed mismatch distribution cannot be significantly distinguished from a distribution expected under past population expansion (Online Resource Fig. S4).

\section{Discussion}

In the present study, we aimed to analyse the genetic diversity and structure of Geoffroy's bat at its north-western European range edge in order to identify factors that may have a negative impact on the conservation status of the species' in this region and to define relevant conservation strategies. In order to adequately address these questions, it was necessary to obtain DNA from a relatively large number of individuals. To that effect, faecal pellets lend themselves to the non-invasive collection of DNA samples. Past studies have reported a high (>70\%; Boston et al. 2012) or very high (>90\%; Puechmaille et al. 2007) proportion of bat faeces yielding DNA of sufficient quality and quantity to generate individualspecific genetic profiles. After the first two amplification reactions, we discarded $54 \%$ of the samples, but managed to generate reliable genetic profiles for the remaining samples with only few errors. Our results were in line with those reported by Viglino et al. (2016), who omitted 39\% of their samples from three Myotis species after genotyping one microsatellite multiplex in quadruplicate and managed to obtain reliable genetic profiles for $53 \%$ of their samples overall. The numerous methodological discrepancies between these four studies make it difficult to identify the reason(s) for the different success rates. Following Luikart et al. (2008), we used a blood and tissue kit to extracted DNA from lysis buffer used to wash the surface of the faecal pellets. While very successful with the faeces of wild bighorn sheep (Ovis canadensis), this method may have been less suitable to deal with bat droppings in general or the inhibitors present in this faecal material in specific. Nevertheless, all studies on bat faecal samples yielded DNA of sufficient quality and quantity to warrant the use of non-invasive genotyping methods in population genetic analysis, which is advantageous for lowering the impact of sampling on threatened/protected species.

\section{Population genetic structure and diversity}

We inferred the presence of four genetic clusters across our north-western European study area. The two clusters B/NL and L/RLP/F extended over a relatively large geographic area. For example, the largest geographic distance between colonies in the L/RLP/F cluster was $285 \mathrm{~km}$ (between Mortehan and Vogisheim). The Austria/Romania cluster also appeared to cover a very large area. However, as the cluster consisted of only two colonies we cannot exclude the possibility that their grouping together was an artefact resulting from uneven sampling (Puechmaille et al. 2016). Further sampling in Eastern Europe would be required to resolve this issue, as well as to understand the spatial extent of the 'Bavarian' cluster.

Similarly to many other bat species from temperate zones, male and female Geoffroy's bats assemble near caves and mines in late summer in a behaviour known as swarming. This behaviour is thought to primarily serve as a promiscuous mating system (van Schaik et al. 2015). The animals hibernate in the underground sites adjacent to the swarming sites (van Schaik et al. 2015). While some males living in or in proximity to nursery colonies possi- 
bly father some offspring (Angell et al. 2013), the fact that gene flow can occur over large distances provides support for the scenario that the majority of the genetic transfer in Geoffroy's bat occurs during late-summer swarming. All the colonies that were part of the same genetic population must thus be connected via the same swarming sites, while genetically distinct colonies must use different ones (see also Rivers et al. 2005).

In both the $\mathrm{B} / \mathrm{NL}$ and the $\mathrm{L} / \mathrm{RLP} / \mathrm{F}$ clusters, the genetic differentiation between nursery colonies gradually increased with the geographic distance between them. Rivers et al. (2005) used genetic methods to show that the proportion of female Natterer's bats (Myotis nattereri) using a specific swarming site declined with distance from their nursery colony to the swarming site. Our results thus seem to suggest that multiple, geographically separate swarming sites are present within the occurrence areas of the different genetic populations. Also females from the same colony appear to be using separate swarming sites, with proximity to the nursery colony being an important factor in the choice of the site. It is important to note, however, that in the case of the L/RLP/F cluster, the IBD pattern was driven by a geographic outlier, implying that the colonies in Luxembourg and neighbouring regions were all connected via a small number of common swarming sites, or perhaps that distance from the nursery colony did not affect the likelihood of visitation of a swarming site.

While the clustering methods did not identify any genetically isolated nursery colonies in North-western Europe, the FCA inferred three outliers from the two main genetic clusters. In all likelihood, the 'Mortehan' colony was an outlier because of a high proportion of individuals with admixed ancestry. It is possible that there was reduced genetic exchange between 'Riemst' and 'Lippelo' and neighbouring colonies, but that both colonies were not (yet) sufficiently differentiated to be inferred as separate genetic populations by the clustering algorithms (see also Puechmaille et al. 2016). 'Lipello' did have the lowest allelic richness and expected unbiased heterozygosity values of all the colonies ('Riemst' was excluded due to low sample size). Currently, there is no information available as to whether the animals from 'Lipello' (and 'Riemst') might be using different swarming sites to the animals in the other B/NL colonies and future research is needed to resolve this question.

Our results of interconnected colonies over a large spatial scale appeared comparable to results reported for the greater horseshoe bat (Rhinolophus ferrumequinum). Colonies of this species from Portugal, Spain, France and Italy formed one genetic cluster that was characterised by a relatively weak IBD pattern (Rossiter et al. 2007; Tournayre et al. 2019). Similarly to Geoffroy's bat, the greater horseshoe bat usually covers between 10 and $60 \mathrm{~km}$ when moving between nursery colonies and hibernation sites, with occasional movement distances of over $100 \mathrm{~km}$ also reported in the literature (Hutterer et al. 2005). Also, the philopatric females form maternity colonies during summer and they mate with the solitary males in spring and autumn in caves (Rossiter et al. 2007). Similarly, Myotis bechsteinii, a forest dwelling bat species with a comparable reproductive behaviour to Geoffroy's bat, appears to form a single widespread geographic cluster in western and central Europe that is also characterised by an IBD pattern (Kerth and Petit 2005; Wright et al. 2018).

\section{Genetic diversity and demographic history}

We hypothesised that, given the location of the study area and the characteristics of the study species, we would find evidence of reduced genetic diversity at the north-western 
range edge. Our results suggested that it was indeed the case for the B/NL cluster, both in terms of mitochondrial and microsatellite diversity, but not the L/RLP/F cluster. It was not clear, however, whether this reduced genetic diversity could be explained by a relatively recent contraction in population size.

The mitochondrial data were consistent with one or more past population expansion event(s), as both the star-like pattern of the haplotype network and tests for neutral molecular evolution supported this assumption. We found evidence for a single European haplotype group, with some haplotype variants shared widely across Europe. A very shallow mitochondrial genetic diversity between distant populations (e.g. Belgium, Germany and Greece) was also observed by Bogdanowicz et al. (2015), who analysed another mitochondrial marker (ND1) in a small number of specimens of Geoffroy's bat. This spatial genetic pattern indicates at least one postglacial population expansion, during which some refugial haplotype variants have been maintained, but simultaneously, new haplotypes have also evolved and increased in frequency due to genetic drift and serial founder events during range expansion.

The number of mitochondrial haplotypes, as well as haplotype and nucleotide diversity generally decreased from south to north, which also seems to be the case in other bat species (Ruedi and Castella 2003; Juste et al. 2004; Bogdanowicz et al. 2015). Surprisingly, however, haplotype and nucleotide diversity were highest in the 'Luxembourg' pre-defined group, as a result of a low number of haplotypes with similar frequencies (see Avise 2000). The average of $\Phi_{\mathrm{ST}}=0.319$ between summer roosts in the L/RLP/F cluster suggested a certain degree of haplotype segregation between nursery colonies, and thus a certain degree of female philopatry (see also Kerth et al. 2000; Castella et al. 2001), possibly resulting in a small(er) number of common haplotypes within a matriline and a limited number of haplotypes with comparable frequency across the cluster as a whole. In contrast to the L/ $\mathrm{RLP} / \mathrm{F}$ cluster, a remarkable decrease of mitochondrial haplotype and nucleotide diversity was detected in the North of Ardennes predefined group, in particular when compared to the adjacent Luxembourg population. In terms of microsatellite diversity, the B/NL cluster also appeared to be genetically less diverse than the adjoining L/RLP/F cluster, as well as the Bavaria cluster.

Based on the microsatellite data, all three tested clusters (B/NL, L/RLP/F, Bavaria) bore signals of a major population contraction in the past, with current population sizes around two orders of magnitude smaller than the ancestral ones. Using the migraine software, Tournayre et al. (2019) in contrast did not find a significant signature of demographic change in colonies and genetic populations of the greater horseshoe bat in Western Europe. In a simulation study the IBD pattern and the sampling intensity affected the false contraction detection rates (FCDR) of migraine in constant-size populations (Leblois et al. 2014). For example, the FCDR reached an average of $14.5 \%$ for scenarios with extremely low IBD and a small sampling scale (not sampling the whole area) which is (presumably) similar to the Bavaria samples, the FCDR reached an average of $9 \%$ for scenarios with low IBD and a large sampling scale which is similar to the B/NL samples, and the FCDR reached an average of $11 \%$ for scenarios with extremely low IBD and a large sampling scale which is similar to the $\mathrm{L} / \mathrm{RLP} / \mathrm{F}$ samples. We can thus be fairly confident that we detected true contractions in all three populations. In the same simulation study (Leblois et al. 2014), the mean relative bias (computed as the sum of differences between observed input values and the values measured by migraine divided by the observed values) was consistently negative 
for current population density (meaning that it overestimated $N$ ) and positive for ancestral population density (meaning that it underestimated $N_{\text {anc }}$ ), which indicates that our ratios are unlikely to have been overestimates of population contraction.

The estimated timing of the population contraction event differed between the three populations. While The L/RLP/F cluster stands out as having had its last major decline in the more ancient past (after the post-glacial expansion), whereas the last major decline in Bavaria happened more recently. Relative to Bavaria, the results did not strongly support a recent major decline in the $\mathrm{B} / \mathrm{NL}$ cluster. Also there was no obvious link between the inferred demographic history and genetic diversity, with the Bavarian cluster having the highest genetic diversity despite a recent population contraction. migraine computes the time in generations since the end of the demographic change scaled by the current population size. It is thus difficult to infer precise time points for the start of the population decline and link it to specific events and processes, even though anthropogenic pressures may have contributed to the recent decline in the Bavaria cluster. Given the large scale of the inferred population contractions, they may also have resulted from a sudden disconnection of the respective clusters from a larger European population (Broquet et al. 2010). Ultimately, a comparison of the genetic diversity in extant individuals and museum specimens is necessary to assess to what extent the documented recent population crash contributed to the reduced genetic diversity in the B/NL cluster, relative to a founder event or an earlier demographic catastrophe.

\section{Conservation implications}

While the literature agrees that Geoffroy's bats avoid open areas and busy roads during foraging (Krull et al. 1991; Gaisler et al. 2009), our results appear to suggest that, at present, habitat fragmentation has not affected the genetic connectivity at larger spatial scales. Indeed, rather than dealing with structured populations and small conservation units that require specific efforts (with the possible exceptions of 'Riemst' and 'Lippelo'; see above), conservation managers face a situation where the same large population occurs across a large geographic scale and multiple political jurisdiction.

Because our results appear to confirm that swarming sites are crucial for gene flow and outbreeding, the identification and conservation of these sites, as well as the closely linked hibernation sites, seem vitally important (see also Parsons et al. 2003) and will affect the conservation of the species beyond the practitioner's immediate area of interest. Moreover, understanding and possibly mitigating the effect of habitat fragmentation and homogenisation on the bats' access to their swarming sites appear to be an important consideration for future research and should be considered when establishing species conservation plans. In addition to measures aimed at optimising foraging habitats, conservation of the functional connectivity between nursery colonies and swarming/hibernation sites also requires crossborder cooperation (Dekker et al. 2013; Gessner et al. 2018).

While the B/NL population at the extreme edge of the north-western European distribution range of Geoffroy's bat had the lowest diversity, the reduction (at nuclear microsatellite loci) was not dramatically low, at least not compared to highly endangered species (Frankham et al. 2009). Estimates of the genetic health of a population based on microsatellite loci ought to be taken with a certain degree of caution and do not inform us about the adaptive potential of a threatened species (de Villemereuil et al. 2019; Shaw 2019). Never- 
theless, genetic monitoring ought to be repeated at regular intervals, especially in the case of the $\mathrm{B} / \mathrm{NL}$ cluster but also elsewhere, in order to track genetic change and assess whether the conservation measures ensure effective connectivity of the population and prevent further declines in genetic diversity.

Acknowledgements We would like to thank Pedro Alves, Laurent Arthur, Femke Batsleer, Kris Boers, Frank Claessens, Thierry Debaere, Marie-Jo Dubourg-Savage, Bernadette Duhaut, Frédéric François, Jean-Louis Gathoye, Astghik Ghazaryan, Birgit Gessner, Hélène Ghyselinck, Liza Glesener, Thibaut Goret, René Janssen, Dorothée Jouan, Thierry Kerveyn, Alex Lefevre, Marzia Mattei-Roesli, Luc Mesmans, Paul Michaux, Thierry Paternoster, Maude Pauly, Luisa Rodrigues, Quentin Smits, Claude Steck, Markus Thies, Jacques Thonnard, Vleermuizenwerkgroep Natuurpunt, Daniela Wieser and Andreas Zahn for providing us with samples.

Authors' contributions ACF, SS and JP conceived and organised the project; AV, RC and MG conceived and performed the project that led to mitochondrial data from Italy and southern Europe; EW, APC, JB and AS performed the laboratory work, JW performed the migraine analysis, AW analysed the mitochondrial data, PN, DD, JD, ML, SLB and JP organised and performed the majority of the field work, GH provided the raw sequences for microsatellite development. ACF wrote the manuscript with contributions by AW and JW. All the authors commented on the manuscript.

Funding The work was support by grants from the Luxembourg Ministry for Environment, Climate and Sustainable Development and the National Natural History Museum of Luxembourg. JW was funded by the Luxembourg research fund FNR (C20/SR/14748041).

Availability of data and material The microsatellite (OL889574-OL889585) and mitochondrial control region sequences (OL889586-OL889631) are available on GenBank An XLSX file containing the geo-referenced microsatellite genotypes is available on Figshare (Frantz et al. 2021).

Code availability Not applicable.

\section{Declarations}

Conflicts of interest/Competing interests The authors have no conflicts of interest to declare that are relevant to the content of this article.

Consent to participate All authors gave consent to participate.

Consent for publication All authors gave consent for publication.

Open Access This article is licensed under a Creative Commons Attribution 4.0 International License, which permits use, sharing, adaptation, distribution and reproduction in any medium or format, as long as you give appropriate credit to the original author(s) and the source, provide a link to the Creative Commons licence, and indicate if changes were made. The images or other third party material in this article are included in the article's Creative Commons licence, unless indicated otherwise in a credit line to the material. If material is not included in the article's Creative Commons licence and your intended use is not permitted by statutory regulation or exceeds the permitted use, you will need to obtain permission directly from the copyright holder. To view a copy of this licence, visit http://creativecommons.org/licenses/by/4.0/.

\section{References}

Angell RL, Butlin RK, Altringham JD (2013) Sexual segregation and flexible mating patterns in temperate bats. PLoS ONE 8:e54194. https://doi.org/10.1371/journal.pone.0054194 
Avise JC (2000) Phylogeography: the history and formation of species. Harvard University Press Cambridge, MA

Belkhir K (2004) 1996-2004 genetix 4.05, logiciel sous Windows TM pour la génétique des populations. https://kimura.univ-montp2.fr/genetix/. Accessed 15 June 2021

Bogdanowicz W, Hulva P, Černá Bolfíková B et al (2015) Cryptic diversity of Italian bats and the role of the Apennine refugium in the phylogeography of the western Palaearctic. Zool J Linnean Soc 174:635-648. https://doi.org/10.1111/zoj.12248

Boston ESM, Puechmaille SJ, Scott DD et al (2012) Empirical assessment of non-invasive population genetics in bats: comparison of DNA quality from faecal and tissue samples. Acta Chiropt 14:45-52. https:// doi.org/10.3161/150811012X654259

Broquet T, Angelone S, Jaquiery J et al (2010) Genetic bottleneck driven by population disconnection. Conserv Biol 24:1596-1605

Broquet T, Petit E (2004) Quantifying genotyping errors in noninvasive population genetics. Mol Ecol 13:3601-3608. https://doi.org/10.1111/j.1365-294X.2004.02352.x

Campbell S, Guay PJ, Mitrovski PJ, Mulder R (2009) Genetic differentiation among populations of a specialist fishing bat suggests lack of suitable habitat connectivity. Biol Conserv 142:2657-2664. https://doi. org/10.1016/j.biocon.2009.06.014

Castella V, Ruedi M (2000) Characterization of highly variable microsatellite loci in the bat Myotis myotis (Chiroptera: Vespertilionidae). Mol Ecol 9:1000-1002. https://doi.org/10.1046/j.1365-294x.2000.00939-6.x

Castella V, Ruedi M, Excoffier L (2001) Contrasted patterns of mitochondrial and nuclear structure among nursery colonies of the bat Myotis myotis. J Evol Biol 14:708-720. https://doi. org/10.1046/j.1420-9101.2001.00331.x

Červený J (1999) Myotis emarginatus (E. Goeffroy, 1806). In: Mitchell-Jones AJ, Amori G, Bogdanowicz W, Kryštufek B, Reijnders PJH, Spitzenberger F, Stubbe M, Thissen JBM, Vohralík V, Zima J (eds) The atlas of European mammals. T \& AD Poyser, London, pp 112-113

Corander J, Waldmann P, Marttinen P, Sillanpää MJ (2004) BAPS 2: enhanced possibilities for the analysis of genetic population structure. Bioinformatics 20:2363-2369. https://doi.org/10.1093/bioinformatics/ bth250

Council of the European Communities (1992) Council Directive 92/43/EEC of 21. May 1992 on the conservation of natural habitats and of wild fauna and flora. OJEC 35:7-50

De Villemereuil P, Rutschmann A, Lee KD, Ewen JG, Brekke P, Santure AW (2019) Little adaptive potential in a threatened passerine bird. Curr Biol 29:889-894. https://doi.org/10.1016/j.cub.2019.01.072

Dekker JJA, Regelink JR, Jansen EA, Brinkmann R, Limpens HJGA (2013) Habitat use by female Geoffroy's bats (Myotis emarginatus) at its two northernmost maternity roosts and the implications for their conservation. Lutra 56:111-120

Dietz M, Pir JB (2021) Geoffroy’s bat-Myotis emarginatus (Geoffroy, 1806). In: In: Hackländer K, Zachos FE (eds) Handbook of the Mammals of Europe. Springer Nature, Switzerland. https://doi. org/10.1007/978-3-319-65038-8

Eckert CG, Samis KE, Lougheed SC (2008) Genetic variation across species' geographical ranges: the central-marginal hypothesis and beyond. Mol Ecol 17:1170-1188. https://doi. org/10.1111/j.1365-294X.2007.03659.x

Excoffier L, Laval G, Schneider S (2005) Arlequin (version 3.0): an integrated software package for population genetics data analysis. Evol Bioinform Online 1:47-50. https://doi.org/10.1177/117693430500100003

Fahrig L (2003) Effects of habitat fragmentation on biodiversity. Annu Rev Ecol Evol Syst 34:487-515. https://doi.org/10.1146/annurev.ecolsys.34.011802.132419

Fleming TH (2019) Bat migration. In: In: Choe JC (ed) Encyclopedia of animal behaviour. Elsevier Academic Press, Cambridge, MA, pp 605-610. https://doi.org/10.1016/B978-0-12-809633-8.20764-4

Frankham R, Ballou JD, Briscoe DA (2009) Introduction to Conservation Genetics, 2nd edn. Cambridge University Press, Cambridge, UK

Frantz AC, Pope LC, Carpenter PJ, Roper TJ, Wilson GJ, Delahay RJ, Burke T (2003) Reliable microsatellite genotyping of the Eurasian badger (Meles meles) using faecal DNA. Mol Ecol 12:1649-1661. https:// doi.org/10.1046/j.1365-294X.2003.01848.x

Frantz AC, Viglino A, Wilwert E et al (2021) Geo-referenced microsatellite data from Myotis emarginatus. figshare. Dataset. https://doi.org/10.6084/m9.figshare.17212124.v2

Frick WF, Kingston T, Flanders J (2019) A review of the major threats and challenges to global bat conservation. Ann NY Acad Sci 1469:5-25. https://doi.org/10.1111/nyas.14045

Fu YX (1997) Statistical tests of neutrality of mutations against population growth, hitchhiking and background selection. Genetics 147:915-925

Fu YX, Li WH (1993) Statistical tests of neutrality of mutations. Genetics 133:693-709

Gaisler J, Řehák Z, Bartonička T (2009) Bat casualties by road traffic (Brno-Vienna). Acta Theriol 54:147155. https://doi.org/10.1007/BF03193170 
Gessner B, Thies M, Schneider S (2018) Erste Wochenstuben der Wimperfledermaus (Myotis emarginatus Geoffroy, 1806) für Rheinland-Pfalz im Bitburger Gutland (Eifelkreis Bitburg-Prüm). Nyctalus $19: 110-123$

Goudet J (1995) FSTAT (vers. 1.2): a computer program to calculate $F$-statistics. J Hered 86:485-486. https:// doi.org/10.1093/oxfordjournals.jhered.a111627

Hardy O, Vekemans X (2002) SPAGeDi: a versatile computer program to analyse spatial genetic structure at the individual or population levels. Mol Ecol Notes 2:618-620. https://doi. org/10.1046/J.1471-8286.2002.00305.X

Harpending HC (1994) Signature of ancient population growth in a low-resolution mitochondrial DNA mismatch distribution. Hum Biol 66:591-600

Hutterer R, Ivanova T, Meyers-Cords C, Rodrigues L (2005) Bat migrations in Europe: A review of banding data and literature. Bundesamt für Naturschutz, Bonn

Hutterer R, Montermann C, Weigt M (2012) A Holocene bat fauna from the Eifel Mountains. Germany Vespertilio 16:159-164

Ibouroi MT, Cheha A, Arnal V et al (2018) The contrasting genetic patterns of two sympatric flying fox species from the Comoros and the implications for conservation. Conserv Genet 19:1425-1437. https://doi. org/10.1007/s10592-018-1111-6

IUCN (2021) The IUCN Red List of Threatened Species. Version 2021-1. https://www.iucnredlist.org. Accessed 1 June 2021

Jaeger JAG, Madrinan LF (2011) Landscape fragmentation in Europe. European Environmental Agency, Luxembourg

Juste J, Ibáñez C, Munoz J, Trujillo D, Benda P, Karataş A, Ruedi M (2004) Mitochondrial phylogeography of the long-eared bats (Plecotus) in the Mediterranean Palaearctic and Atlantic Islands. Mol Phylogenet Evol 31:1114-1126. https://doi.org/10.1016/j.ympev.2003.10.005

Kerth G, Petit E (2005) Colonization and dispersal in a social species, the Bechstein's bat (Myotis bechsteinii). Mol Ecol 14:3943-3950. https://doi.org/10.1111/j.1365-294X.2005.02719.x

Kerth G, Mayer F, König B (2000) Mitochondrial DNA (mtDNA) reveals that female Bechstein's bats live in closed societies. Mol Ecol 9:793-800. https://doi.org/10.1046/j.1365-294x.2000.00934.x

Krull D, Schumm A, Metzner W, Neuweiler G (1991) Foraging areas and foraging behavior in the notcheared bat, Myotis emarginatus (Vespertilionidae). Behav Ecol Sociobiol 28:247-253. https://oi. org/10.1007/BF00175097

Kunz TH, Braun de Torrez E, Bauer DM, Lobova TA, Fleming TH (2011) Ecosystem services provided by bats. Ann NY Acad Sci 1223:1-38. https://doi.org/10.1111/j.1749-6632.2011.06004.x

Leblois R, Pudlo P, Neron J, Bertaux F, Beeravolu CR, Vitalis R, Rousset F (2014) Maximum-likelihood inference of population size contractions. Mol Biol Evol 31:2805-2823. https://doi.org/10.1093/ $\mathrm{molbev} / \mathrm{msu} 212$

Leigh JW, Bryant D (2015) popart: full-feature software for haplotype network construction. Methods Ecol Evol 6:1110-1116. https://doi.org/10.1111/2041-210X.12410

Luikart G, Zundel S, Rioux D et al (2008) Low genotyping error rates and noninvasive fecal DNA samples from bighorn sheep. J Wildl Manage 72:299-304. https://doi.org/10.2193/2006-006

Meinig HU, Boye P (2009) A review of negative impact factors threatening mammal populations in Germany. Folia Zool 58:279-290

Meyer CFJ, Kalko EKV, Kerth G (2009) Small-scale fragmentation effects on local genetic diversity in two phyllostomid bats with different dispersal abilities in Panama. Biotropica 41:95-102. https://doi. org/10.1111/j.1744-7429.2008.00443.x

Miller SA, Dykes DD, Polesky HF (1988) A simple salting-out procedure for extracting DNA from human nucleated cells. Nucleic Acids Res 16:1215. https://doi.org/10.1093/nar/16.3.1215

Moussy C, Hosken DJ, Mathews F, Smith GC, Aegerter JN, Bearhop S (2013) Migration and dispersal patterns of bats and their influence on genetic structure. Mammal Rev 43:183-195. https://doi. org/10.1111/j.1365-2907.2012.00218.x

Nei M (1978) Estimation of average heterozygosity and genetic distance from a small number of individuals. Genetics 89:583-590

Ochman K (2003) Late Pleistocene and Holocene bats (Chiroptera) from the Komarowa Cave (CracowCzęstochowa Upland, Poland) - preliminary results. Acta Zool Cracov 46:73-84

Parsons KN, Jones G (2003) Dispersion and habitat use by Myotis daubentonii and Myotis nattereri during the swarming season: Implications for conservation. Anim Conserv 6:283-290. https://doi.org/10.1017/ S1367943003003342

Pir JB, Dietz M (2018) Populationsdichte und Lebensraumnutzung der Wimperfledermaus (Myotis emarginatus Geoffroy, 1806) an ihrer nördlichen Verbreitungsgrenze in Luxemburg. Bull Soc Nat luxemb 120:107-121 
Piraccini R (2016) Myotis emarginatus. The IUCN Red List of Threatened Species, e.T14129A22051191. https://doi.org/10.2305/IUCN.UK.2016-2.RLTS.T14129A22051191.en

Pritchard JK, Stephens M, Donnelly P (2000) Inference of population structure using multilocus genotype data. Genetics 155:945-959

Puechmaille S (2016) The program STRUCTURE does not reliably recover the correct population structure when sampling is uneven: subsampling and new estimators alleviate the problem. Mol Ecol 16:608627. https://doi.org/10.1111/1755-0998.12512

Puechmaille S, Mathy G, Petit E (2007) Good DNA from bat droppings. Acta Chiropterologica, 9:269-276. https://doi.org/10.3161/1733-5329(2007)9[269:GDFBD]2.0.CO;2

Ramos-Onsins SE, Rozas J (2002) Statistical properties of new neutrality tests against population growth. Mol Biol Evol 19:2092-2100. https://doi.org/10.1093/oxfordjournals.molbev.a004034

Raymond M, Rousset F (1995) GENEPOP (version 1.2): a population genetics software for exact tests and ecumenicism. J Hered 86:248-249. https://doi.org/10.1093/oxfordjournals.jhered.a111573

Rivers NM, Butlin RK, Altringham JD (2005) Genetic population structure of Natterer's bats explained by mating at swarming sites and philopatry. Mol Ecol 14:4299-4312. https://doi. org/10.1111/j.1365-294X.2005.02748.x

Rogers AR, Harpending H (1992) Population-growth makes waves in the distribution of pairwise genetic distances. Mol Biol Evol 9:552-569. https://doi.org/10.1093/oxfordjournals.molbev.a040727

Rousset F (1997) Genetic differentiation and estimation of gene flow from $F$-statistics under isolation by distance. Genetics 45:1219-1228

Rousset F, Leblois R (2012) Likelihood-based inferences under a coalescent model of isolation by distance: two-dimensional habitats and confidence intervals. Mol Biol Evol 29:957-973. https://doi.org/10.1093/ molbev/msr262

Rossiter SJ, Benda P, Dietz C, Zhang S, Jones G (2007) Rangewide phylogeography in the greater horseshoe bat inferred from microsatellites: implications for population history, taxonomy and conservation. Mol Ecol 16:4699-4714. https://doi.org/10.1111/j.1365-294X.2007.03546.x

Rozas J, Ferrer-Mata A, Sánchez-DelBarrio JC, Guirao-Rico S, Librado P, Ramos-Onsins SE, SánchezGracia A (2017) DnaSP 6: DNA sequence polymorphism analysis of large data sets. Mol Biol Evol 34:3299-3302. https://doi.org/10.1093/molbev/msx248

RuediM,CastellaV(2003)Genetic consequences of the iceages on nurseries of the bat Myotis myotis: amitochondrial and nuclear survey. Mol Ecol 12:1527-1540. https://doi.org/10.1046/j.1365-294X.2003.01828.x

Rueness EK, Jorde PE, Hellborg PE, Stenseth NC, Ellegren H, Jakobsen KA (2003) Cryptic population structure in a large, mobile mammalian predator: the Scandinavian lynx. Mol Ecol 12:2623-2633. https:// doi.org/10.1046/j.1365-294X.2003.01952.x

Schunger I, Dietz C, Merdschanova et al (2004) Swarming of bats (Chiroptera, Mammalia) in the Vodnite Dupki cave (Central Balkan National Park, Bulgaria). Acta Zool Bulg 56:323-330

Shaw RG (2019) From the past to the future: considering the value and limits of evolutionary prediction. Am Nat 193:1-10. https://doi.org/10.1086/700565

Tajima F (1989) The effect of change in population size on DNA polymorphism. Genetics 123:453-464

Topál G (2001) Myotis emarginatus (Geoffroy's bat)—Wimperfledermaus. In: Krapp F (ed) Handbuch der Säugetiere Europas. Band 4/I: Fledertiere. Aula Verlag, Kempten, pp 369-404

Tournayre O, Pons JB, Leuchtmann M et al (2019) Integrating population genetics to define conservation units from the core to the edge of Rhinolophus ferrumequinum western range. Ecol Evol 9:1227212290. https://doi.org/10.1002/ece3.5714

Van der Meij T, Van Strien AJ, Haysom KA et al (2015) Return of the bats? A prototype indicator of trends in European bat populations in underground hibernacula. Mamm Biol 80:170-177. https://doi. org/10.1016/j.mambio.2014.09.004

Van Schaik J, Janssen R, Bosch T, Haarsma A-J, Dekker JJA, Kranstauber B (2015) Bats swarm where they hibernate: compositional similarity between autumn swarming and winter hibernation assemblages at five under-ground sites. PLoS ONE 10:e0130850. https://doi.org/10.1371/journal.pone.0130850

Verhoeven KJF, Simonsen KL, McIntyre LM (2005) Implementing false discovery rate control: increasing your power. Oikos 108:643-647. https://doi.org/10.1111/j.0030-1299.2005.13727.x

Voigt CC, Kingston T (2016) Bats in the Anthropocene. In: In: Voigt CC, Kingston T (eds) Bats in the Anthropocene: conservation of bats in a changing world. Springer, Heidelberg, pp 1-9. https://doi. org/10.1007/978-3-319-25220-9_1

Viglino A (2012) Study of variability and genetic structure of European populations of Myotis emarginatus and Myotis capaccinii (Chiroptera, Vespertilionidae). Dissertation, University of Bologna

Viglino A, Caniglia R, Ruiz-Gonzalez A et al (2016) What can we learn from faeces? Assessing genotyping success and genetic variability in three mouse-eared bat species from non-invasive genetic sampling. Hystrix 27:150-157. https://doi.org/10.4404/hystrix-27.2-11835 
Weir BS, Cockerham CC (1984) Estimating $F$-statistics for the analysis of population structure. Evolution 38:1358-1370. https://doi.org/10.1111/j.1558-5646.1984.tb05657.x

Wright PGR, Hamilton PB, Schofield H, Glover A, Damant C, Davidson-Watts I, Mathews F (2018) Genetic structure and diversity of a rare woodland bat, Myotis bechsteinii: Comparison of continental Europe and Britain. Conserv Genet 19:777-787. https://doi.org/10.1007/s10592-018-1053-z

Publisher's Note Springer Nature remains neutral with regard to jurisdictional claims in published maps and institutional affiliations.

\section{Authors and Affiliations}

\section{Alain C. Frantz ${ }^{1}$ Andrea Viglino ${ }^{2}$ - Elodie Wilwert ${ }^{1}$ - Ana-Paula Cruz ${ }^{1}$. Julian Wittische ${ }^{1,3} \cdot$ Alexander M. Weigand ${ }^{1}$. Jacky Buijk ${ }^{1} \cdot$ Pierrette Nyssen ${ }^{4}$. Daan Dekeukeleire ${ }^{5}$ Jasja J.A. Dekker ${ }^{6} \cdot$ Gavin J. Horsburgh $^{7} \cdot$ Simone Schneider $^{1,8}$. Mara Lang $^{8} \cdot$ Romolo Caniglia $^{9} \cdot$ Marco Galaverni $^{10} \cdot$ Anna Schleimer $^{1}$. Szilárd-Lehel Bücs ${ }^{11}$ - Jacques B. Pir ${ }^{1}$}

Alain C. Frantz

alain.frantz@mnhn.lu

1 Musée National d'Histoire Naturelle, 25, rue Muenster, L-2160 Luxembourg, Luxembourg

2 University of Bologna, Bologna, Italy

3 Fondation Faune-Flore, Luxembourg, Luxembourg

4 Natagora, Namur, Belgium

5 Terrestrial Ecology Unit, University of Ghent, Ghent, Belgium

6 Jasja Dekker Dierecologie, Arnhem, The Netherlands

7 NERC Biomolecular Analysis Facility, University of Sheffield, Sheffield, UK

$8 \quad$ Nature conservation syndicate SICONA, Olm, Luxembourg

9 Unit for Conservation Genetics, Italian Institute for Environmental Protection and Research, Bologna, Italy

10 Conservation Unit, WWF Italia, Rome, Italy

11 Centre for Bat Research and Conservation, Cluj-Napoca, Romania 